\title{
Fibrin clot structure remains unaffected in young, healthy individuals after transient exposure to diesel exhaust
}

\author{
Sofian Metassan1,2, Michael N Routledge2, Andrew J Lucking³, Shirley Uitte de Willige1, Helen Philippou, \\ Nicholas $L$ Mills $^{3}$, David E Newby ${ }^{3}$ and Robert AS Ariëns*1
}

\begin{abstract}
Exposure to urban particulate matter has been associated with an increased risk of cardiovascular disease and thrombosis. We studied the effects of transient exposure to diesel particles on fibrin clot structure of 16 healthy individuals (age 21-44). The subjects were randomly exposed to diesel exhaust and filtered air on two separate occasions. Blood samples were collected before exposure, and 2 and 6 hours after exposure. There were no significant changes on clot permeability, maximum turbidity, lag time, fibre diameter, fibre density and fibrinogen level between samples taken after diesel exhaust exposure and samples taken after filtered air exposure. These data show that there are no prothrombotic changes in fibrin clot structure in young, healthy individuals exposed to diesel exhaust.
\end{abstract}

\section{Findings}

Exposure to urban particulate matter (PM) air pollution has been associated with increased risk of cardiovascular disease and mortality [1]. Peters et al. showed that exposure to PM has an immediate effect on acute cardiovascular events [2], with a peak in admission to hospital within as little as 2 hours after exposure. Hamster models showed increased arterial and venous thrombosis less than 1 hour after exposure to diesel exhaust [3]. In agreement with this, human subjects who were transiently exposed to dilute diesel exhaust had increased ex vivo thrombus formation [4]. A study by Baccarelli et al. showed hypercoagulability after transient PM exposure [5]. These studies suggest prothrombotic effects due to short term exposure to PM.

In vitro and in vivo data suggest that the biological effects of PM are mostly attributable to ultrafine particulate matter (UFPM) with an aerodynamic diameter of less than $100 \mathrm{~nm}$ [6-8]. These particles have a large surface area per unit mass and are therefore capable of carrying larger amounts of harmful compounds on their surface [9]. Furthermore, some reports suggested that UFPM

* Correspondence: r.a.s.ariens@leeds.ac.uk

1 Division of Cardiovascular and Diabetes Research, Section on Mechanisms of Thrombosis, Leeds Institute for Genetics Health and Therapeutics, Faculty of Medicine and Health, University of Leeds, Leeds, UK

Full list of author information is available at the end of the article may be translocated into the circulation either passively or by active transport mechanisms [10,11]. Detectable levels of UFPM have been found in the liver, kidney, spleen and heart of exposed animals $[6,12,13]$. Exposure to PM, and UFPM in particular, has been associated with systemic inflammation and increased blood coagulability [5,14-16].

Coagulation produces a fibrin clot which has threedimensional network characteristics. The structure of the fibrin network is an important determinant of clot rigidity, susceptibility to fibrinolysis and cell interactions. We recently found that in vitro addition of PM to fibrinogen changes clot structure producing a heterogeneous network with densely knit fibrin interspersed with looser areas [17]. We therefore tested the hypothesis that transient exposure to diesel exhaust may lead to changes to fibrin structure and function in vivo.

Sixteen healthy subjects aged $26 \pm 5$ (mean \pm SD, range 21- 44) were randomly exposed to filtered air or dilute diesel engine exhaust (PM: $350 \mu \mathrm{g} / \mathrm{m}^{3}$ ) for 2 hours performing moderate exercise on a bicycle for $15 \mathrm{~min}$ alternated with $15 \mathrm{~min}$ rest periods. This exposure level is regularly reached during rush-hour traffic in large cities [18]. The study was approved by the local research Ethics Committee (Edinburgh), in accordance with the Declaration of Helsinki. Each subject agreed to participation in 
the study by written informed consent [4]. The study had a double-blind cross-over design, hence the same subjects, unaware of the exposure type, were exposed to air on one occasion and to diesel on another (minimum time between the exposures was 2 weeks). Blood was collected on citrate before and 2 and 6 hours after exposure. Platelet poor plasma was prepared by centrifugation and samples were stored below $-40^{\circ} \mathrm{C}$.

Fibrin clot permeation analysis was performed on clots made from plasma by the addition of $1 \mathrm{U} / \mathrm{ml}$ thrombin and $10 \mathrm{mM} \mathrm{CaCl}_{2}$. Permeation was performed and the permeation constant Ks, which describes average poresize in $\mathrm{cm}^{2}$, was calculated as described [17,19]. Fibrin polymerisation was investigated by optical density (OD) measurements at a wavelength of $340 \mathrm{~nm}$ every $12 \mathrm{sec}$ onds in a 96 well microtiterplate using an ELx808 BioTek microplate reader (Winooski, VT, USA). Plasma was diluted 6 -fold and clot formation was initiated by addition of $0.03 \mathrm{U} / \mathrm{ml}$ thrombin and $10 \mathrm{mM} \mathrm{CaCl}_{2}$. Lag time (time to increase in OD of > 0.01) and maximum OD (ODmax) were measured.

Fibrin clots for laser scanning confocal microscopy were made in a $\mu$-slide VI (Ibidi, Germany) by the addition of $0.5 \mathrm{U} / \mathrm{ml}$ thrombin and $10 \mathrm{mM} \mathrm{CaCl}_{2}$ to plasma (diluted 2-fold in $0.05 \mathrm{M}$ Tris- $\mathrm{HCl}, 0.1 \mathrm{M} \mathrm{NaCl}, \mathrm{pH}$ 7.4). The slide was kept in a moist chamber and confocal microscopy was performed on a Leica TSC-SP2 as described $[17,20]$. Fibre diameters were analysed using the Leica software. Fibre density was calculated as the number of fibres crossing a straight line of fixed length across the scanfield.

Fibrinogen levels were measured in plasma using ELISA. Rabbit anti-human fibrinogen IgG (DAKO A0080), diluted 1/8000, was used as capture antibody. Bovine serum albumin $(1 \%[\mathrm{w} / \mathrm{v}])$ was used to block nonspecific sites. Plasma (diluted 1/128,000 and 1/256,000) was subsequently incubated for 1 hour. Goat polyclonal anti-fibrinogen HRP-conjugated IgG (Abcam ab7539), diluted 1/16,000 was used for detection. The assay was developed using OPD tablets (DAKO). All incubations were carried out at room temperature. Fibrinogen levels were calibrated against a standard curve $(1.56 \mathrm{ng} / \mathrm{ml}$ to 25 $\mathrm{ng} / \mathrm{ml}$ ) of purified human fibrinogen (Calbiochem, UK).

For each subject, we calculated the change in fibrin parameters from baseline to 2 hours after exposure and from baseline to 6 hours after exposure. Paired t-test was used to test whether changes in fibrin parameters were different between exposure to air and exposure to diesel. $\mathrm{P}$-values less than 0.05 were taken as statistically significant.

We analysed a total of 93 samples. For one subject, samples were unavailable after diesel exhaust exposure. Table 1 summarises the data obtained. Compared to before exposure, maximum turbidity (ODmax, indicative of average fibre mass-length ratio) was significantly increased 2 hours after exposure to filtered air ( $\mathrm{p}=$ 0.032). However, this effect was not seen 2 hours after exposure to diesel exhaust. There was a decrease in lag time 6 hours after diesel exhaust exposure, but this value did not differ significantly from either the pre-exposed value ( $p=0.082)$ or from the lag time 6 hours after filtered air exposure $(\mathrm{p}=0.56)$. There were no significant changes in Ks (analysis of fibrin pore-structure by permeability), or in fibre diameter and fibre density as analysed by confocal microscopy after exposure to both diesel exhaust and filtered air. Fibre density is inversely proportional to Ks and its lack of changes after diesel exhaust is in agreement with the permeability measurement. Fibrinogen level was significantly decreased 6 hours after exposure to filtered air $(p=0.025)$. However, this fall in fibrinogen level was not significantly different compared to fibrinogen levels 6 hours after diesel exhaust exposure $(\mathrm{p}=0.26)$.

Fibrin is formed at the site of damaged blood vessels and its structure is an essential determinant of the elastic properties of the clot and susceptibility to fibrinolysis. Fibrin clots with decreased $\mathrm{Ks}$ (as a result of tighter fibrin networks), increased fibre density and thinner fibres are commonly found in patients with acute coronary syndrome [21,22]. Since exposure to UFPM is associated with cardiovascular disease, we hypothesised that exposure to diesel exhaust leads to altered fibrin clot structure. In addition, we recently observed changes in fibrin clot structure upon exposure to PM in vitro. However, here we find that fibrin properties in plasma from volunteers after transient diesel exhaust exposure remained remarkably similar to those in the samples of the same subjects after exposure to filtered air, showing that at least in healthy, young individuals fibrin structure is not affected by PM exposure at typical environmental exposure levels.

Due to the transient nature of the diesel exposure in this study, we cannot predict the effects of more chronic exposure to pollution on fibrin clot structure. Chronic exposure to PM likely precipitates and aggravates pulmonary disease and existing cardiovascular disease. People chronically exposed to high PM concentration have been shown to have a greater risk of pulmonary and cardiovascular diseases compared to those living in less polluted areas [23]. As our study population involved young, healthy subjects, we cannot predict the effect of exposure to PM on fibrin structure in susceptible individuals such as the elderly, diabetic patients and patients with chronic obstructive pulmonary disease [24]. It would also be of interest to examine the effect of higher occupational exposures (e.g. bus garage workers) on fibrin clot structure. Based on our data we conclude that transient expo- 
Table 1: Fibrin clot structure in young, healthy volunteers exposed to filtered air and diesel exhaust

\begin{tabular}{|c|c|c|c|c|c|c|c|}
\hline & \multirow[b]{2}{*}{ Pre-exposed } & \multirow[b]{2}{*}{$2 \mathrm{hr}$} & \multirow[b]{2}{*}{$6 \mathrm{hr}$} & \multirow[b]{2}{*}{$\Delta \mathbf{2 h r}$} & \multirow[b]{2}{*}{$\Delta 6 \mathrm{hr}$} & \multicolumn{2}{|c|}{$\begin{array}{l}\text { P values for comparison of } \\
\text { changes between filtered air } \\
\text { and diesel exhaust }\end{array}$} \\
\hline & & & & & & $\Delta 2 \mathrm{hr}$ & $\Delta 6 \mathrm{hr}$ \\
\hline \multicolumn{8}{|l|}{ Filtered air $(n=16)$} \\
\hline $\mathrm{Ks}\left(\times 10^{-9} \mathrm{~cm}^{2}\right)$ & $5.17 \pm 1.48$ & $5.27 \pm 2.64$ & $5.13 \pm 1.22$ & $0.10 \pm 2.01$ & $-0.04 \pm 0.92$ & - & - \\
\hline ODmax & $0.230 \pm 0.051$ & $0.255 \pm 0.078$ & $0.233 \pm 0.059$ & $0.025 \pm 0.042$ & $0.003 \pm 0.021$ & - & - \\
\hline Lag time (seconds) & $917 \pm 321$ & $906 \pm 352$ & $922 \pm 482$ & $-11 \pm 302$ & $5 \pm 385$ & - & - \\
\hline Fibre Diameter (nm) & $458 \pm 18$ & $457 \pm 18$ & $470 \pm 25$ & $-1 \pm 18$ & $12 \pm 24$ & - & - \\
\hline $\begin{array}{r}\text { Fibre Density } \\
\text { (fibres } / 120 \mu \mathrm{m} \text { ) }\end{array}$ & $7.3 \pm 1.6$ & $7.5 \pm 1.6$ & $7.2 \pm 1.8$ & $0.2 \pm 1.1$ & $-0.1 \pm 2.1$ & - & - \\
\hline $\begin{array}{r}\text { Fibrinogen level } \\
(\mathrm{mg} / \mathrm{ml})\end{array}$ & $2.05 \pm 0.43$ & $2.12 \pm 0.43$ & $1.81 \pm 0.31$ & $0.07 \pm 0.48$ & $-0.24 \pm 0.36$ & - & - \\
\hline \multicolumn{8}{|l|}{ Diesel Exhaust $(n=15)$} \\
\hline $\mathrm{Ks}\left(\times 10^{-9} \mathrm{~cm}^{2}\right)$ & $4.94 \pm 1.89$ & $5.44 \pm 1.46$ & $4.85 \pm 1.26$ & $0.51 \pm 1.95$ & $-0.09 \pm 1.32$ & 0.55 & 0.90 \\
\hline ODmax & $0.246 \pm 0.044$ & $0.244 \pm 0.039$ & $0.238 \pm 0.039$ & $-0.002 \pm 0.024$ & $-0.008 \pm 0.036$ & $0.03 \S$ & 0.17 \\
\hline Lag time (seconds) & $846 \pm 223$ & $788 \pm 226$ & $737 \pm 201$ & $-58 \pm 270$ & $-109 \pm 226$ & 0.64 & 0.56 \\
\hline Fibre Diameter (nm) & $455 \pm 21$ & $459 \pm 16$ & $465 \pm 21$ & $4 \pm 21.7$ & $10 \pm 24.4$ & 0.54 & 0.91 \\
\hline $\begin{array}{r}\text { Fibre Density } \\
\text { (fibres } / 120 \mu \mathrm{m})\end{array}$ & $7.8 \pm 1.4$ & $8.1 \pm 1.7$ & $8.1 \pm 1.7$ & $0.3 \pm 1.2$ & $0.3 \pm 1.2$ & 0.97 & 0.59 \\
\hline $\begin{array}{r}\text { Fibrinogen level } \\
(\mathrm{mg} / \mathrm{ml})\end{array}$ & $2.10 \pm 0.45$ & $2.08 \pm 0.41$ & $1.96 \pm 0.22$ & $-0.02 \pm 0.33$ & $-0.14 \pm 0.32$ & 0.76 & 0.26 \\
\hline
\end{tabular}

Data represents before exposure (pre-exposed), 2 hours after exposure ( $2 \mathrm{hr}), 6 \mathrm{hours}$ after exposure $(6 \mathrm{hr})$, the difference between $2 \mathrm{hours}$ and pre-exposed $(\Delta 2 \mathrm{hr}$ ) and the difference between 6 hours and pre-exposed ( $\Delta 6 \mathrm{hr}$ ). The values are mean \pm standard deviation. $P$ values were calculated by paired t-test.

Bold typeset indicates values that were significantly different from baseline.

$\S$ indicates the changes after diesel exhaust exposure were significantly different from those after filtered air exposure.

sure to diesel in young, apparently healthy individuals is not associated with changes in fibrin clot structure.

\section{List of abbreviations used}

ELISA: enzyme-linked immunosorbent assay; HRP: Horseradish peroxidise; IgG: immunoglobulin; Ks: Darcy or permeation constant, measure of the pore-size in fibrin clots; ODmax: maximum optical density reached in turbidity assays, indicative of average fibre mass-length ratio; OPD: o-phenylenediamine dihydrochloride; PM: particulate matter; UFPM: ultrafine particulate matter

\section{Competing interests}

The authors declare that they have no competing interests.

\section{Authors' contributions}

SM performed the fibrin structure analysis and fibrinogen measurements and wrote the manuscript. MNR designed the study and provided critical comments. AJL, NLM and DEN designed and performed the transient diesel exposure study and provided critical comments. SUdW helped with the fibrinogen measurements and statistical analysis and provided critical comments. HP helped with experimental design and provided critical comments. RASA designed the study and wrote the manuscript. All authors read and approved the final manuscript.

\section{Acknowledgements}

SM is supported by a PhD studentship from the Ministry of Health of Brune Darussalam. AJL, NLM, DEN are supported by the British Heart Foundation. SUdW, HP and RASA are supported by the British Heart Foundation (PG06/089/ $21244, P G / 08 / 002 / 24285)$. The funding bodies had no role in the study design, the collection, analysis and interpretation of data, writing of the manuscript or in the decision to submit the manuscript for publication.

\section{Author Details}

1Division of Cardiovascular and Diabetes Research, Section on Mechanisms of Thrombosis, Leeds Institute for Genetics Health and Therapeutics, Faculty of Medicine and Health, University of Leeds, Leeds, UK, 2Molecular Epidemiology Unit, Leeds Institute for Genetics Health and Therapeutics, Faculty of Medicine and Health, University of Leeds, Leeds, UK and ${ }^{3}$ Centre for Cardiovascular Science, University of Edinburgh, Edinburgh, UK

Received: 17 March 2010 Accepted: 16 June 2010 Published: 16 June 2010 


\section{References}

1. Franchini M, Mannucci PM: Short-term effects of air pollution on cardiovascular diseases: outcomes and mechanisms. J Throm Haemost 2007, 5:2169-2174.

2. Peters A, von Klot S, Heier M, Trentinaglia I, Hörmann A, Wichmann HE, Löwel $\mathrm{H}$ : Exposure of traffic and the onset of myocardial infarction. $N$ Engl J Med 2004, 351:1721-1730.

3. Nemmar A, Hoet PH, Dinsdale D, Vermylen J, Hoylaerts MF, Nemery B: Diesel exhaust particles in lung acutely enhance experimental peripheral thrombosis. Circulation 2003, 107:1202-1208.

4. Lucking AJ, Lundback M, Mills NL, Faratian D, Barath SL, Pourazar J, Cassee FR, Donaldson K, Boon NA, Badimon JJ, Sandstrom T, Blomberg A, Newby DE: Diesel exhaust inhalation increases thrombus formation in man. Eur Heart J 2008, 29:3043-3051.

5. Baccarelli A, Zanobetti A, Martinelli I, Grillo P, Hou L, Giacomini S, Bonzin M, Lanzani G, Mannucci PM, Bertazzi PA, Schwartz J: Effects of exposure to air pollution on blood coagulation. J Thromb Haemost 2007, 5:252-260.

6. Nemmar A, Vanbilloen $H$, Hoylaerts MF, Hoet PH, Verbruggen A, Nemery B: Passage of intratracheally instilled ultrafine particles from the lung into the systemic circulation in hamster. Am J Respir Crit Care Med 2001 164:1665-1668

7. Monteiller C, Tran L, MacNee W, Faux S, Jones A, Miller B, Donaldson K: The pro-inflammatory effects of low-toxicity low-solubility particles, nanoparticles and fine particles, on epithelial cells in vitro: the role of surface area. Occup and Environ Med 2007, 64:609-615.

8. Radomski A, Jurasz P, Alonso-Escolano D, Drews M, Morandi M, Malinski T, Radomski MW: Nanoparticle-induced platelet aggregation and vascular thrombosis. Br J Pharmacol 2005, 146:882-893.

9. Donaldson K, Stone V: Current hypotheses on the mechanisms of toxicity of ultrafine particles. Ann 1st Super Sanita 2003, 39:405-410.

10. Furuyama A, Kanno S, Kobayashi T, Hirano S: Extrapulmonary translocation of intratracheally instilled fine and ultrafine particles via direct and alveolar macrophage-associated routes. Arch Toxicol 2009, 83:429-437.

11. Mühlfeld C, Gehr P, Rothen-Rutishauser B: Translocation and cellular entering mechanisms of nanoparticles in the respiratory tract. Swiss Med Wkly 2008, 138:387-391.

12. Oberdorster G, Sharp Z, Atudorei V, Elder A, Gelein R, Lunts A, Kreyling W, Cox C: Extrapulmonary translocation of ultrafine carbon particles following whole-body inhalation exposure of rats. J Toxicol Environ Health 2002, 65:1531-1543.

13. Takenaka S, Karg E, Roth C, Schulz H, Ziesenis A, Heinzmann U, Schramel P, Heyder J: Pulmonary and systemic distribution of inhaled ultrafine silver particles in rats. Environ Health Perspect 2001, 109:547-551.

14. Nikasinovic L, Just J, Sahraoui F, Seta N, Grimfeld A, Momas I: Nasal inflammation and personal exposure to fine particles PM2.5 in asthmatic children. J Allergy Clin Immunol 2006, 117:1382-1388.

15. Ruckerl R, Abald-Mulli A, Koenig W, Schneider A, Woelke G, Cyrys J, Heinrich J, Marder V, Frampton M, Wichmann HE, Peters A: Air pollution and markers of inflammation and coagulation in patients with coronary heart disease. Am J Respir Crit Care Med 2006, 173:432-441.

16. van Eeden SF, Tan WC, Suwa T, Mukae H, Terashima T, Fujii T, Qui D, Vincent R, Hogg JC: Cytokines involved in the systemic inflammatory response induced by exposure to particulate matter air pollutants (PM10). Am J Respir Crit Care Med 2001, 164:826-830.

17. Metassan S, Charlton AJ, Routledge MN, Scott DJA, Ariëns RAS: Alteration of fibrin clot properties by ultrafine particulate matter. Thromb Haemost 2010, 103:103-113.

18. Mills NL, Tornqvist H, Robinson SD, Gonzalez M, Darnley K, MacNee W, Boon NA, Donaldson K, Blomberg A, Sandstrom T, Newby DE: Diesel exhaust inhalation causes vascular dysfunction and impaired endogenous fibrinolysis. Circulation 2005, 112:3930-3936.

19. Standeven KF, Grant PJ, Carter AM, Scheiner T, Weisel JW, Ariëns RAS: Functional analysis of the fibrinogen Aalpha Thr312Ala polymorphism: effects on fibrin structure and function. Circulation 2003, 107:2326-2330

20. Ajjan R, Lim BC, Standeven KF, Harrand R, Dolling S, Phoenix F, Greaves R, Abou-Saleh RH, Connell S, Smith DA, Weisel JW, Grant PJ, Ariëns RAS: Common variation in the $\mathrm{C}$-terminal region of the fibrinogen betachain: effects on fibrin structure, fibrinolysis and clot rigidity. Blood 2008, 111:643-650.
21. Collet JP, Allali Y, Lesty C, Tanguy ML, Silvain J, Ankri A, Blanchet B, Dumaine R, Gianetti J, Payot L, Weisel JW, Montalescot G: Altered fibrin architecture is associated with hypofibrinolysis and premature coronary artherothrombosis. Arterioscler Thromb Vasc Biol 2006 26:2567-2573.

22. Fatah K, Silveira A, Tornvall P, Karpe F, Blombäck M, Hamsten A: Proneness to formation of tight and rigid fibrin gel structures in men with myocardial infarction at a young age. Thromb Haemost 1996, 76:535-540

23. Brag AL, Zanobetti A, Schwartz J: The lag structure between particulate air pollution and respiratory and cardiovascular deaths in 10 US cities. J Occup Environ Med 2001, 43:927-933.

24. MacNee W, Donaldson K: Mechanism of lung injury caused by PM10 and ultrafine particles with special reference to COPD. Eur Respir J 2003, 21(Suppl):47-51.

doi: 10.1186/1743-8977-7-17

Cite this article as: Metassan et al., Fibrin clot structure remains unaffected in young, healthy individuals after transient exposure to diesel exhaust Particle and Fibre Toxicology 2010, 7:17

\section{Submit your next manuscript to BioMed Central and take full advantage of:}

- Convenient online submission

- Thorough peer review

- No space constraints or color figure charges

- Immediate publication on acceptance

- Inclusion in PubMed, CAS, Scopus and Google Scholar

- Research which is freely available for redistribution

Submit your manuscript at www.biomedcentral.com/submit
C Biomed Central 